\title{
Uma avaliação do PRONAF no período 1995-2018
}

José Miguel Pretto ${ }^{1}$

Carlos Henrique Horn²

\begin{abstract}
Resumo
Este artigo apresenta uma avaliação do desempenho do crédito à agricultura familiar brasileira entre os anos de 1995 a 2018 no âmbito do Programa Nacional de Fortalecimento da Agricultura Familiar (PRONAF). Examinam-se estatísticas de volume financiado, número de contratos e distribuição dos recursos quanto a regiões, tipo de beneficiário e tipo de cultura. Os dados mostram a forte expansão do montante de crédito a partir de 2003, seguida de contração iniciada com a recessão econômica de 2015-2016, bem como a concentração dos recursos na região Sul, em agricultores de maior porte e na lavoura de soja. $O$ artigo contrasta, ainda, estes resultados com as expectativas despertadas com a criação do PRONAF em meados dos anos 1990.
\end{abstract}

Palavras-chave: Agricultura familiar. Crédito rural. Política pública.

\begin{abstract}
This paper aims at analysing the performance of PRONAF, a rural credit policy directed at Brazilian family farming, from 1995 to 2018. Evidence comprises credit volume, number of contracts, and the distribution of the resources according to regions, kind of beneficiary and crops. The outcomes show a strong expansion of both credit volume and number of contracts from 2003 on, followed by a deep contraction associated to the economic recession of 2015-2016, as well as some degree of credit concentration in the Southern region of the country, higher-size family farming, and producers of soya. The paper also contrasts actual outcomes with the expectations arisen the creation of PRONAF in the mid-1990s.
\end{abstract}

Keywords: Family farming. Rural credit. Public policy.

\section{Introdução}

O Programa Nacional de Fortalecimento da Agricultura Familiar (PRONAF) consolidou-se como o principal instrumento de política pública de apoio à agricultura familiar brasileira desde sua criação em meados da década de $1990 .^{3}$ As origens do PRONAF situam-se num duplo movimento - de um lado, social ou político; de outro, teórico - ocorrido no Brasil nos primeiros

\footnotetext{
${ }^{1}$ Doutor em Políticas Sociais e Direitos Humanos (PPGPSDH/UCPel). pretto.poa.rs@gmail.com.

2 Ph.D. Industrial Relations (LSE/Universidade de Londres). Professor da Faculdade de Ciências Econômicas da UFRGS. chhorn@portoweb.com.br.

${ }^{3}$ Em 1995, ano da criação do PRONAF, os temas atinentes à agricultura familiar estavam sob a responsabilidade do então Ministério da Agricultura, do Abastecimento e da Reforma Agrária (MAARA). No ano de 1999, a Medida Provisória n. 1.911-12, de 25 de novembro, instituiu o Ministério da Política Fundiária e do Desenvolvimento Agrário - renomeado Ministério do Desenvolvimento Agrário pela Medida Provisória n. 1.999-14, de 13 de janeiro de 2000 -, atribuindo-lhe competência para a promoção do desenvolvimento sustentável do segmento rural constituído pelos agricultores familiares. Com a reorganização ministerial prevista na Lei n. 10.683, de 28 de maio de 2003, consolidou-se o Ministério do Desenvolvimento Agrário (MDA), ao qual coube a condução das políticas de fortalecimento da agricultura familiar durante a maior parte do período investigado neste artigo. Por fim, antes mesmo da conclusão do processo de impeachment da presidente Dilma, o novo governo de Michel Temer tomou a decisão de extinguir o MDA, o que se materializou na Medida Provisória n. 726, de 12 de maio de 2016 (convertida com alterações na Lei n. 13.341, de 29 de setembro de 2016). A MP também repassou as responsabilidades da promoção do desenvolvimento sustentável do segmento rural constituído pelos agricultores familiares ao Ministério do Desenvolvimento Social e Agrário. Essa competência, todavia, acabou transferida por força do Decreto n. 8.780, de 27 de maio de 2016, para a Casa Civil da Presidência da República, a qual veio a abrigar a Secretaria Especial de Agricultura Familiar e do Desenvolvimento Agrário, a Secretaria da Agricultura Familiar e outras estruturas associadas ao tema. Este era o arranjo institucional em vigor ao final de 2018, antes da posse do presidente Jair Bolsonaro.
}

COLÓQUIO - Revista do Desenvolvimento Regional - Faccat - Taquara/RS - v. 17, n. 1, jan./mar. 2020 
anos daquela década. Os principais agentes do movimento político foram o Departamento Nacional dos Trabalhadores Rurais da Central Única dos Trabalhadores (DNTR/CUT) e a Confederação Nacional dos Trabalhadores na Agricultura (CONTAG), instituição tradicional do sistema sindical brasileiro e que havia se integrado ao processo que conduzira à fundação da CUT, em 1983. Estas associações eram responsáveis por iniciativas de defesa dos interesses dos pequenos produtores, concentradas na Região Sul do país sob o nome de "Jornadas de Luta". O sucesso das Jornadas em dar visibilidade a reivindicações dos agricultores familiares resultou em sua unificação num vibrante movimento nacional que veio a se chamar "Grito da Terra Brasil" (GRISA; SCHNEIDER, 2014, p. 79). Dentre os vários temas que motivavam a luta dos agricultores ao final dos anos 1980 e no início dos 1990, constavam o crédito fundiário, a assistência técnica, a pesquisa, a educação e a formação profissional, a infraestrutura e a habitação. Destes, destacava-se a necessidade de uma política de crédito subsidiado para investimentos em infraestrutura e inovação nos pequenos estabelecimentos rurais. Esperava-se que esses investimentos levassem a uma maior produção de alimentos e segurança alimentar para o país, ao desenvolvimento de uma agricultura ecologicamente sustentável e à fixação das pessoas no meio rural (NUNES, 2007).

No campo teórico, pode-se afirmar que houve uma mudança no entendimento sobre o futuro e as possibilidades da agricultura familiar em uma economia capitalista. Até o final dos anos 1980, a literatura especializada brasileira era caudatária de um enfoque marxista sobre a agricultura e se referia, sobretudo, ao debate clássico entre Lênin e Kautsky acerca da possibilidade, ou impossibilidade, de sobrevivência ou permanência dos pequenos do campo em face do inevitável progresso da grande agricultura. A principal conclusão deste debate apontava para o destino trágico de todos aqueles que dependessem da posse ou propriedade de pequenas extensões de terra, os quais seriam fatalmente superados ou engolidos pelo latifúndio. ${ }^{4}$

Este entendimento da dinâmica socioeconômica do campo refletia-se na terminologia adotada para se referir ao segmento da agricultura familiar. Termos como pequeno agricultor, minifiundiário, camponês ou sem-terra, eram utilizados para diferenciar um tipo de trabalhador e/ou de produção na agricultura que não aquela fundada no grande agricultor, agronegócio ou agricultura empresarial. Nos anos 1990, o uso crescente de referências à agricultura familiar e a seu agente, o agricultor familiar, viria acompanhado da perda de relevância, senão que pelo simples abandono, da tese da subordinação inevitável dessa agricultura às condições capitalistas de produção no campo, ganhando destaque a possibilidade de sobrevivência associada a medidas de política agrícola e a políticas específicas para o segmento (GRISA; SCHNEIDER, 2014).

Dentre as políticas específicas para os agricultores familiares, sobressaía-se a do crédito subsidiado. Neste contexto, a criação do PRONAF esteve associada, fundamentalmente, à aceitação de um programa público de crédito específico para pequenos agricultores que contasse com recursos orçamentários em sua execução. Foi a Resolução BACEN n. 2191, de 24 de agosto de 1995, que instituiu, "no âmbito do crédito rural, o Programa Nacional de Fortalecimento da Agricultura Familiar (PRONAF), destinado ao apoio financeiro às atividades agropecuárias exploradas mediante emprego direto da força de trabalho do produtor e de sua família" (Art. $1^{\circ}$ ). Essa mesma Resolução fixou as condições dos financiamentos, definindo seus beneficiários,

\footnotetext{
${ }^{4}$ Para uma revisão compreensiva sobre este debate, ver Abramovay (1998), capítulos 1 e 2.
} 
encargos, limites de crédito para investimentos e outros aspectos, e autorizou as Secretarias de Política Agrícola, do então Ministério da Agricultura, do Abastecimento e da Reforma Agrária, e de Acompanhamento Econômico, do Ministério da Fazenda, a adotarem medidas e promoverem ajustes necessários à implementação de suas disposições. O programa, que passou por inúmeras alterações normativas desde sua criação, veio a reunir um conjunto mais amplo de instrumentos de apoio à agricultura familiar, incluindo, dentre outros, "[...] o crédito rural, o financiamento de infraestruturas e serviços básicos municipais (Pronaf Infraestrutura), e a capacitação e profissionalização dos agricultores familiares e demais atores relacionados com a categoria" (GRISA; WESZ JUNIOR; BUCHWEITZ, 2014, p. 324).

No presente artigo, analisamos o desempenho do PRONAF com base em estatísticas do crédito destinado à agricultura familiar brasileira no período entre 1995 , ano de sua criação, e 2018. Destacamos a evolução dos valores contratados e do número de contratos e a distribuição dos recursos segundo regiões, culturas e grau de capitalização dos agricultores, assinalando virtudes e problemas na execução do programa. Assim, na sequência do texto, delimitamos o público beneficiário da política na seção 2; analisamos os grandes números de desempenho da oferta de crédito ao segmento entre 1995 e 2018 na seção 3; e, por fim, consideramos esse desempenho sob as óticas da distribuição regional, por tipo de beneficiário e por tipo de culturas na seção 4. O artigo apresenta ao final algumas considerações em que se contrastam os resultados do PRONAF com expectativas originalmente despertadas por sua criação.

\section{0 público beneficiário do PRONAF}

O principal público beneficiário do PRONAF é constituído pelos agricultores familiares. Do ponto de vista normativo, agricultores familiares são aqueles que possuem ou conduzem estabelecimentos familiares, regulamentados pela Lei n. 11.326, de 24 de julho de 2006. Conforme o Art. 3 dessa Lei, alterado pela Lei n. 12.512, de 14 de outubro de 2011, considerase:

\footnotetext{
(...) agricultor familiar e empreendedor familiar rural aquele que pratica atividades no meio rural, atendendo, simultaneamente, aos seguintes requisitos:

I - não detenha, a qualquer título, área maior do que 4 (quatro) módulos fiscais;

II - utilize predominantemente mão-de-obra da própria família nas atividades econômicas do seu estabelecimento ou empreendimento;

III - tenha percentual mínimo da renda familiar originada de atividades econômicas do seu estabelecimento ou empreendimento, na forma definida pelo Poder Executivo;

IV - dirija seu estabelecimento ou empreendimento com sua família.
}

Além dos agricultores familiares, o PRONAF também contempla como públicos beneficiários os silvicultores, os aquicultores, os extrativistas, os povos indígenas e os quilombolas, todos definidos conforme o Art. $3^{\circ}, \S 2^{\circ}$, da Lei n. 11.326, para fins de enquadramento no programa.

De acordo com o Censo Agropecuário IBGE de 2006, havia 4.367.902 estabelecimentos familiares no Brasil, representando $84,4 \%$ do total de estabelecimentos agropecuários. Os agricultores familiares ocupavam uma área de 80,25 milhões de hectares, ou seja, 24,3\% da área 
ocupada por estabelecimentos agropecuários no país. Estes resultados mostram uma estrutura agrária bastante concentrada, em que os estabelecimentos não familiares, ainda que representassem apenas $15,6 \%$ do total, ocupavam $75,7 \%$ da área destinada a atividades agropecuárias. A área média dos estabelecimentos familiares atingia 18,37 hectares, ao passo que a dos não familiares era de 309,18 hectares (FRANÇA; DEL GROSSI; MARQUES, 2009). ${ }^{5}$

Dentre os estabelecimentos familiares, também se observava grande diferenciação. Em estudo da FAO e do INCRA com base nos dados do Censo Agropecuário de 1995/96, é apresentada uma categorização da agricultura familiar brasileira conforme estratos de renda (GUANZIROLI; CARDIM, 2000). ${ }^{6} \mathrm{O}$ estudo mostra que, dentre os agricultores familiares, menos de $10 \%$ dos estabelecimentos são considerados de maiores rendas, porém abrangem $22,2 \%$ da área de agricultura familiar. No extremo oposto, havia $46 \%$ de estabelecimentos classificados como quase sem renda, que detinham tão somente $29,1 \%$ da área. A Tabela 1 apresenta os dados da estrutura fundiária brasileira de acordo com o estudo.

Tabela 1 - Distribuição dos estabelecimentos agropecuários e área média, por categoria e tamanho do estabelecimento, Brasil, 1995/96

\begin{tabular}{lrrrrr}
\hline Categoria de & \multicolumn{2}{c}{ Estabelecimentos } & \multicolumn{2}{c}{ Área total } & Área média \\
\cline { 2 - 6 } estabelecimento & \multicolumn{1}{c}{ Número } & \multicolumn{1}{c}{$\%$} & Mil hectares & \multicolumn{1}{c}{ Hectares } \\
\hline Total & $\mathbf{4 . 8 5 9 . 8 6 4}$ & $\mathbf{1 0 0 , 0}$ & $\mathbf{3 5 3 . 6 1 1}$ & $\mathbf{1 0 0 , 0}$ & $\mathbf{7 2 , 7 6}$ \\
Familiares & 4.139 .369 & 85,2 & 107.768 & 30,5 & 26,03 \\
Maiores rendas & 406.291 & 8,4 & 24.141 & 6,8 & 59,42 \\
Renda média & 993.751 & 20,4 & 33.810 & 9,6 & 34,02 \\
Renda baixa & 823.547 & 16,9 & 18.218 & 5,2 & 22,12 \\
Quase sem renda & 1.915 .780 & 39,4 & 31.599 & 8,9 & 16,49 \\
Patronal & 554.501 & 11,4 & 240.042 & 67,9 & 432,90 \\
Instituições religiosas & 7.143 & 0,1 & 263 & 0,1 & 36,79 \\
Entidades públicas & 158.719 & 3,3 & 5.530 & 1,6 & 34,84 \\
Não identificado & 132 & 0,0 & 8 & 0,0 & 62,73 \\
\hline
\end{tabular}

Fonte: Guanziroli e Cardim (2000). Elaborado pelos autores.

No período abrangido por nossa análise, a condição operacional básica de acesso aos recursos de financiamento do PRONAF era a Declaração de Aptidão ao PRONAF (DAP). De acordo com a regulamentação original do programa (Resolução BACEN n. 2191, de 24 de agosto de 1995), a obtenção do DAF estava condicionada a que os agricultores preenchessem os seguintes critérios:

a) explore parcela de terra na condição de proprietário, posseiro, arrendatário ou parceiro; b) não mantenha empregado permanente, sendo admitido o recurso eventual à ajuda de terceiros quando a natureza sazonal da atividade agrícola o exigir; c) não detenha a qualquer título, área superior a quatro Módulos Fiscais; d) no mínimo, $80 \%$ de sua renda bruta anual seja proveniente da exploração agropecuária ou extrativa; e) resida na propriedade ou em aglomerado urbano ou rural próximos (BIANCHINI, 2015, p. 25).

\footnotetext{
${ }^{5}$ Até a finalização deste artigo, o IBGE não havia divulgado dados do Censo Agropecuário de 2017 que permitissem utilizar uma informação mais atualizada para os propósitos de nossa análise.

${ }^{6}$ Não há registro de estudo recente que utilize uma categorização dos estabelecimentos da agricultura familiar semelhante à do estudo coordenado por Guanziroli e Cardim (2000).
} 
Em 2017, o Decreto n. 9.064, de 31 de maio, instituiu o Cadastro Nacional da Agricultura Familiar (CAF), onde passaram a ser registrados os beneficiários da política nacional da agricultura familiar e outros públicos. Esse cadastro substituiu a Declaração de Aptidão ao PRONAF para fins de acesso às ações e às políticas públicas destinadas às Unidades Familiares de Produção Agrária (UFPA) e aos empreendimentos familiares rurais.

\section{Evolução do volume de crédito e do número de contratos do PRONAF}

No ano inicial de suas operações, o PRONAF celebrou apenas 32.000 contratos num valor total de $\mathrm{R} \$$ 93,0 milhões (MATTEI, 2006). A partir de 1996, no entanto, os números se multiplicaram consideravelmente e as contratações seguiram uma trajetória de crescimento continuado, passando de 332.828 operações nesse ano até atingir um pico de 2.551.497 contratos em 2006 (Figura 1). Os múltiplos efeitos da crise financeira iniciada nos Estados Unidos em 2007, todavia, também alcançaram as operações de crédito à agricultura familiar no Brasil. Assim, houve um recuo até o ponto de 1.550 .749 contratos celebrados no ano de 2008. A partir de 2009, observam-se oscilações nesse indicador, com registro de crescimento até 2013 (1.988.525 contratos) e tendência oposta a partir de então quando declina fortemente para 1.036.868 contratos em 2017, sendo seguido por uma tênue recuperação no ano de 2018 (1.232.250 contratos). Os resultados são expressivos: dado que em 2006 havia 4.367 .902 estabelecimentos familiares no Brasil, o número de contratos, como equivalente do número de estabelecimentos em 2006, oscilou entre 7,6\% (mínimo em 1996) e 58,4\% (máximo em 2006), sendo que a média anual do número de contratos em todo o período equivaleu a $31,4 \%$ do número de estabelecimentos.

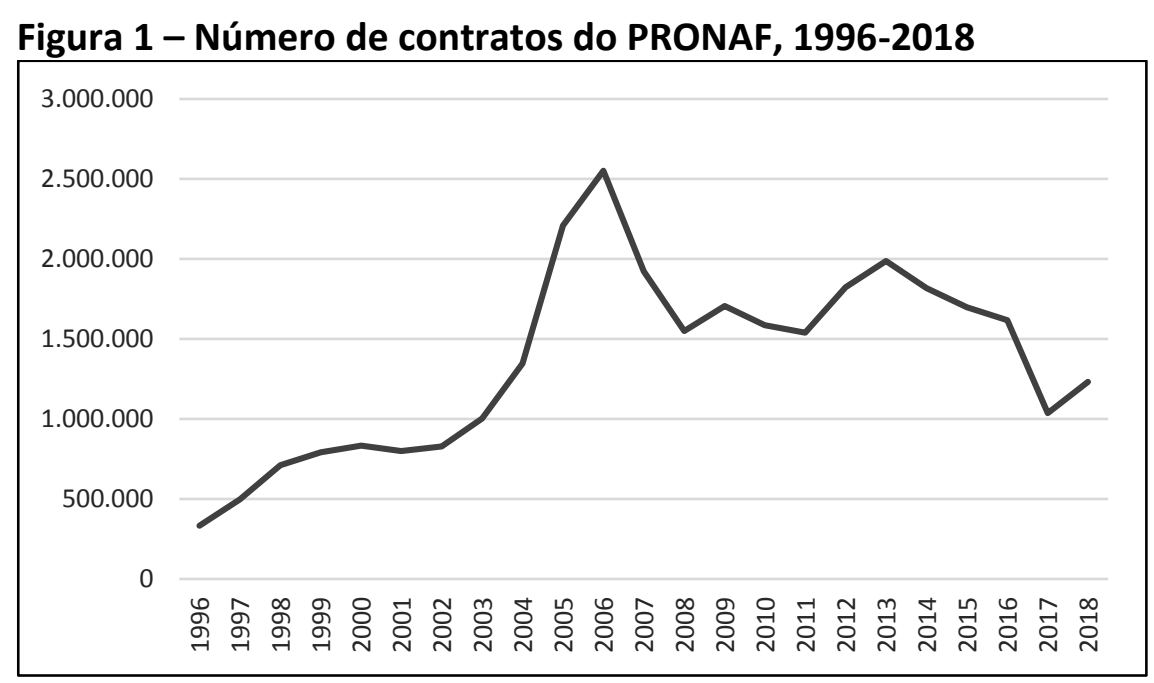

Fonte: Mattei (2006) para 1996-1998; BACEN para 1999-2018. Elaborado pelos autores.

O montante de recursos contratados nas operações do PRONAF também experimentou uma tendência de crescimento, a qual se sustentou até o ano de 2014. Como se observa na Figura 2, após o período de implantação nos anos de 1995 e 1996, o volume de crédito oscilou entre R\$ 5,8 bilhões e R\$ 6,4 bilhões, a preços constantes de 2018, entre os anos de 1997 e 2002. A partir do ano de 2003 , todavia, esses valores decolaram em uma trajetória de forte crescimento, salvo 
pelo ano crítico de 2007, vindo a atingir o montante recorde de $\mathrm{R} \$ 31,4$ bilhões em 2014, um patamar quase cinco vezes mais elevado do que se observara em 2002. Entretanto, com a emergência da recessão econômica a partir de 2015, os recursos contratados no PRONAF sofreram redução continuada até o vale no ano de 2017, quando totalizaram $R \$ 21,7$ bilhões. Em 2018, não obstante certo crescimento em relação ao ano anterior, o nível do crédito foi quase um quarto menor do que no ano de 2014.

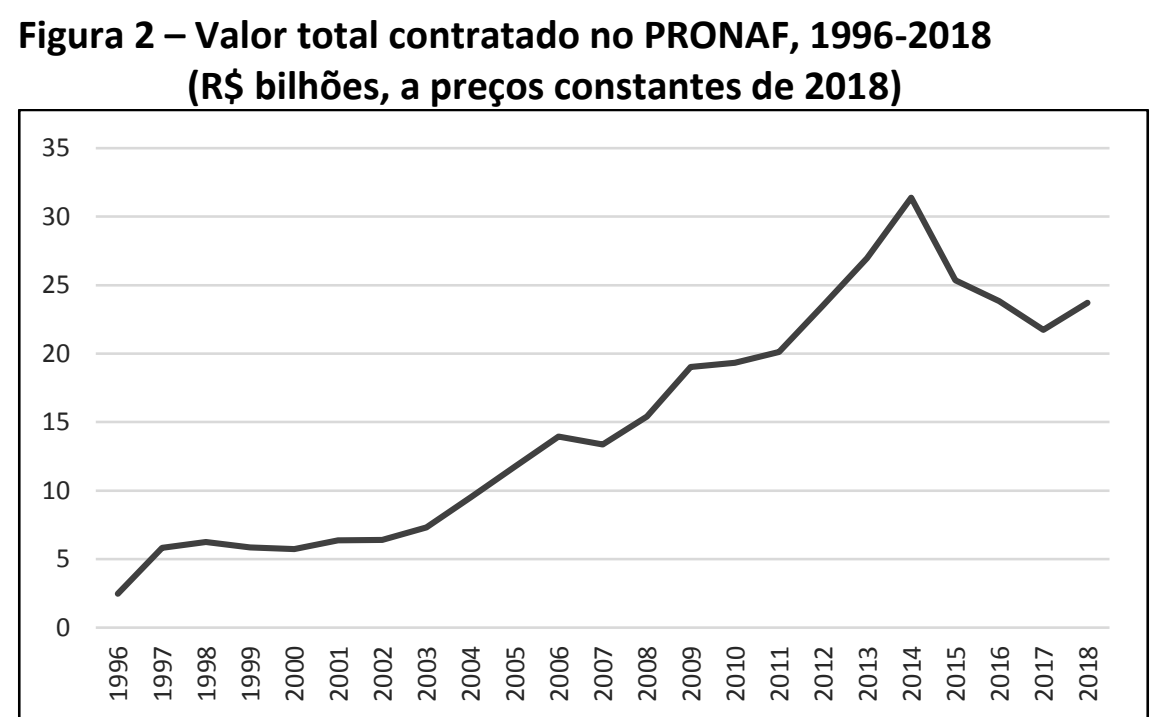

Nota: valores deflacionados pelo IPCA-IBGE.

Fonte: Mattei (2006) para PRONAF em 1996-1998; BACEN para PRONAF em 1999-2018; Ipeadata para IPCA. Elaborado pelos autores.

Considerando que a evolução do número de contratos e do volume de crédito não traçam linhas paralelas, interessa examinar o comportamento do valor médio das operações contratadas no PRONAF. A trajetória desse indicador no período de 1996 a 2018, medido em reais a preços constantes de 2018, é apresentada na Figura 3.

Figura 3 - Valor médio dos contratos do PRONAF, 1996-2018

(RȘ, a preços constantes de 2018)

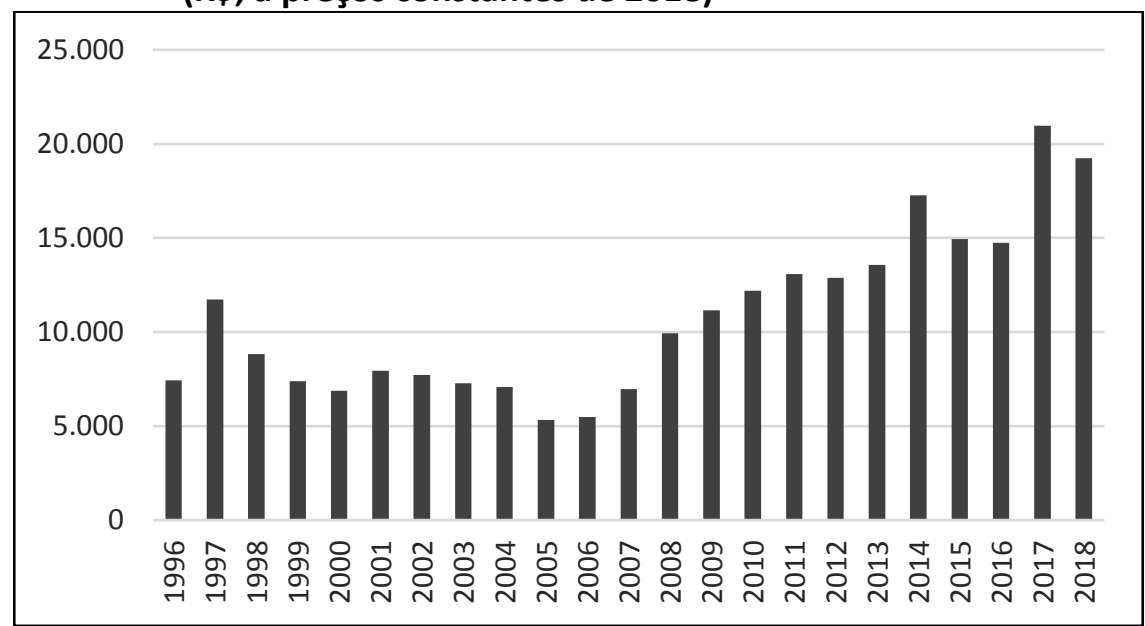

Nota: valores deflacionados pelo IPCA-IBGE.

Fonte: Mattei (2006) para PRONAF em 1996-98; BACEN para PRONAF em 1999-2018;

Ipeadata para IPCA. Elaborado pelos autores. 
À exceção do ano de 1997, o valor médio das operações do PRONAF evidencia uma leve redução entre os anos iniciais do programa e o ano de 2006, oscilando entre $R \$ 5,5$ mil e $R \$ 8,8$ mil a preços constantes de 2018. A partir do ano de 2007, contrariamente, observa-se uma firme tendência de aumento do valor médio dos contratos até atingir o pico de R\$ 20,9 mil em 2017, quando se situou num patamar 3,8 vezes maior do que em 2006. Grosso modo, o comportamento inicial de leve redução no valor médio esteve associado à forte elevação no número de contratos, enquanto que a diminuição progressiva no montante de contratos foi acompanhada de um aumento no valor médio contratado.

Os dados agregados do PRONAF mostram que a evolução do programa até o ano de 2006 abarcou um contingente crescente de agricultores familiares, incluindo provavelmente os de menores porte e grau de capitalização. A título de ilustração, o número de contratos celebrados no ano de 2006 correspondia aproximadamente ao total de estabelecimentos familiares classificados como de rendas alta, média e baixa na estrutura fundiária brasileira segundo o estudo coordenado por Guanziroli e Cardim (2000) com base no Censo Agropecuário 1995/96 (Tabela 1). De modo contrário, a expansão subsequente dos recursos destinados pelo PRONAF até o ano de 2014 fez-se acompanhar por um declínio no número de contratos (queda de $28,7 \%$ em relação a 2006), e, consequentemente, pelo aumento no valor médio das operações, que alcançou R\$ 17,3 mil nesse ano, indicando algum tipo de ajustamento em prejuízo dos agricultores menos capitalizados e, portanto, em piores condições de contratar volumes mais elevados de crédito. Essa tendência atingiu seu pico no ano de 2017, quando o valor médio das operações aumentou para $\mathrm{R} \$ 20,9$ mil em meio a um quadro agravado de redução geral no total de recursos e no número de contratos.

\section{Distribuição regional e por culturas}

Desde sua origem, o PRONAF tem sido um programa caracteristicamente "sulista". A Tabela 2 mostra a distribuição do crédito aos agricultores dos estados da região Sul em anos situados mais para o final de cada uma das três décadas de execução desta política pública. Nos demais anos, a evidência disponível registra resultados semelhantes de concentração do crédito do PRONAF no Sul do país. 
Tabela 2 - Distribuição dos recursos do PRONAF aos estados da região Sul, 1999/2018

\begin{tabular}{|c|c|c|c|c|c|}
\hline \multirow{2}{*}{ Ano } & \multirow{2}{*}{ Região } & \multicolumn{2}{|c|}{ Contratos } & \multicolumn{2}{|c|}{ Valor (R\$ mil, a preços correntes) } \\
\hline & & Número & $(\%)$ & Total & $(\%)$ \\
\hline \multirow{5}{*}{1999} & Brasil & 791.677 & 100,0 & 1.776 .951 & 100,0 \\
\hline & Região Sul & 473.231 & 59,8 & 1.003 .007 & 56,5 \\
\hline & RS & 251.229 & 31,7 & 472.369 & 26,6 \\
\hline & SC & 110.084 & 13,9 & 263.900 & 14,9 \\
\hline & PR & 111.918 & 14,1 & 266.737 & 15,0 \\
\hline \multirow{5}{*}{2008} & Brasil & 1.550 .749 & 100,0 & 8.664 .729 & 100,0 \\
\hline & Região Sul & 543.777 & 35,1 & 4.711.213 & 54,4 \\
\hline & RS & 291.644 & 18,8 & 2.358 .615 & 27,2 \\
\hline & SC & 113.361 & 7,3 & 1.069 .743 & 12,4 \\
\hline & PR & 138.772 & 8,9 & 1.282 .855 & 14,8 \\
\hline \multirow{5}{*}{2018} & Brasil & 1.232 .250 & 100,0 & 23.706 .326 & 100,0 \\
\hline & Região Sul & 398.200 & 32,3 & 13.387 .357 & 56,5 \\
\hline & RS & 196.855 & 16,0 & 6.207 .060 & 26,2 \\
\hline & SC & 90.724 & 7,4 & 3.233 .554 & 13,6 \\
\hline & PR & 110.621 & 9,0 & 3.946 .743 & 16,6 \\
\hline
\end{tabular}

Fonte: BACEN, Anuário Estatístico do Crédito Rural e Matriz de Dados do Crédito Rural. Elaborado pelos autores.

Em geral, a segunda região em relevância na absorção dos recursos do PRONAF tem sido a região Sudeste. No ano de 2018 , essa região realizou $13,7 \%$ dos contratos do programa, com alocação de $\mathrm{R} \$ 3.941 .865$ mil (16,6\% do total nacional) aos agricultores familiares, especialmente do estado de Minas Gerais. A região Nordeste, onde se encontra metade do público potencialmente beneficiário do programa, aparece normalmente apenas em terceiro lugar no indicador de valor, com montante de $\mathrm{R} \$ 3.037 .823$ mil ou $12,8 \%$ do crédito em 2018 , tendo sido, todavia, responsável por 46,7\% dos contratos nesse ano (FRANÇA; DEL GROSSI; MARQUES, 2009; GRISA; SCHNEIDER, 2014). A Tabela 3 apresenta a distribuição dos recursos do PRONAF segundo as unidades da federação e regiões no ano de 2018.

A concentração de recursos do PRONAF na região Sul tem o Nordeste como claro contraponto. Outro aspecto dessa diferença de desempenho está no indicador de valor médio dos contratos (Tabela 3). Nesse caso, enquanto a média sulista equivalia a $174,5 \%$ da média nacional em 2018, o mesmo dado para o Nordeste era de 27,4\%. Assim, a média do valor contratado no Sul foi 6,4 vezes maior do que a do Nordeste naquele ano. Dentre os estados nordestinos, o Rio Grande do Norte, a Paraíba e o Piauí registraram os menores valores médios, entre $\mathrm{R} \$ 4.300$ e $\mathrm{R} \$ 4.690$ por contrato. 
Tabela 3 - Distribuição dos recursos e valor médio dos contratos do PRONAF, por unidades da federação e regiões, 2018

\begin{tabular}{|c|c|c|c|c|c|}
\hline \multirow[t]{2}{*}{ Região e UF } & \multicolumn{2}{|c|}{ Contratos } & \multicolumn{2}{|c|}{$\begin{array}{l}\text { Valor (R\$ mil, a preços } \\
\text { correntes) }\end{array}$} & \multirow{2}{*}{$\begin{array}{c}\text { Valor médio (R\$, } \\
\text { a preços } \\
\text { correntes) }\end{array}$} \\
\hline & Número & (\%) & Total & (\%) & \\
\hline Brasil & 1.232 .250 & 100,0 & 23.706.326 & 100,0 & 19.238 \\
\hline Sul & 398.200 & 32,3 & 13.387 .357 & 56,5 & 33.620 \\
\hline RS & 196.855 & 16,0 & 6.207 .060 & 26,2 & 31.531 \\
\hline SC & 90.724 & 7,4 & 3.233 .554 & 13,6 & 35.642 \\
\hline PR & 110.621 & 9,0 & 3.946 .743 & 16,6 & 35.678 \\
\hline Sudeste & 169.026 & 13,7 & 3.941 .865 & 16,6 & 23.321 \\
\hline MG & 129.253 & 10,5 & 2.521 .475 & 10,6 & 19.508 \\
\hline ES & 19.146 & 1,5 & 679.572 & 2,9 & 35.494 \\
\hline SP & 15.993 & 1,3 & 598.710 & 2,5 & 37.436 \\
\hline $\mathrm{RJ}$ & 4.634 & 0,4 & 142.107 & 0,6 & 30.666 \\
\hline Nordeste & 575.276 & 46,7 & 3.037 .823 & 12,8 & 5.281 \\
\hline BA & 167.297 & 13,6 & 822.693 & 3,5 & 4.918 \\
\hline MA & 56.477 & 4,6 & 362.933 & 1,5 & 6.421 \\
\hline CE & 76.179 & 6,2 & 373.679 & 1,6 & 4.905 \\
\hline PE & 69.284 & 5,6 & 380.656 & 1,6 & 5.494 \\
\hline $\mathrm{PI}$ & 69.510 & 5,6 & 326.004 & 1,4 & 4.690 \\
\hline AL & 29.126 & 2,4 & 212.483 & 0,9 & 7.295 \\
\hline PB & 54.643 & 4,4 & 243.315 & 1,0 & 4.452 \\
\hline SE & 19.865 & 1,6 & 174.925 & 0,7 & 9.806 \\
\hline RN & 32.895 & 2,7 & 141.435 & 0,6 & 4.300 \\
\hline Centro-Oeste & 42.561 & 3,4 & 1.740 .147 & 7,3 & 40.886 \\
\hline MT & 19.824 & 1,6 & 938.017 & 4,0 & 47.317 \\
\hline GO & 15.875 & 1,3 & 588.948 & 2,5 & 37.099 \\
\hline MS & 6.807 & 0,5 & 210.276 & 0,9 & 30.891 \\
\hline DF & 55 & 0,0 & 2.905 & 0,0 & 52.819 \\
\hline Norte & 47.187 & 3,8 & 1.599 .134 & 6,7 & 33.889 \\
\hline RO & 22.690 & 1,8 & 980.689 & 4,1 & 43.221 \\
\hline PA & 14.319 & 1,2 & 300.485 & 1,3 & 20.985 \\
\hline$A C$ & 3.576 & 0,3 & 142.355 & 0,6 & 39.808 \\
\hline TO & 3.843 & 0,3 & 98.136 & 0,4 & 25.536 \\
\hline $\mathrm{RR}$ & 1.318 & 0,1 & 41.404 & 0,2 & 31.414 \\
\hline AM & 836 & 0,1 & 21.990 & 0,1 & 26.304 \\
\hline AP & 605 & 0,0 & 14.075 & 0,1 & 23.265 \\
\hline
\end{tabular}

Fonte: BACEN, Anuário Estatístico do Crédito Rural e Matriz de Dados do Crédito Rural. Elaborado pelos autores.

A concentração dos recursos na região Sul do país pode ser justificada apenas parcialmente em função da distribuição regional dos estabelecimentos familiares, uma vez que, em que pese o elevado número de agricultores familiares no Sul, é na região Nordeste que se concentra a maior parte dos estabelecimentos. Sem procurar esgotar a questão, cabe aventar duas hipóteses explicativas, não mutuamente exclusivas, deste perfil de concentração regional do PRONAF. A primeira hipótese relaciona-se à mobilização política que deu origem ao programa. A persistente pressão de movimentos de agricultores familiares e de outros setores do meio rural da região Sul em favor de políticas públicas direcionadas ao agricultor de menor porte nos anos 
1990 indicaria, também, a existência de um público, por assim dizer, pronto para acessar um programa específico de crédito. Já a segunda hipótese considera o associativismo típico dos agricultores familiares da região. Assim, a reunião desses agricultores em cooperativas de produção ampliaria sua produtividade e asseguraria canais de comercialização, integrando-os com mercados mais distantes e melhorando suas condições de acesso ao crédito sob a ótica dos emprestadores. Em vínculo bastante próximo com as cooperativas de produção, os agricultores familiares da região Sul também contam com a atuação de sistemas de cooperativas de crédito e de instituições financeiras públicas regionais que irrigam o segmento com recursos oriundos do PRONAF.

Ao se examinarem, por sua vez, os dados do PRONAF segundo o tipo de lavoura beneficiado por seus recursos, observa-se uma notável mudança de perfil no curso de vinte anos entre 1999 e 2018. A Tabela 4 mostra os valores de financiamento do PRONAF Custeio segundo o tipo de lavoura nos anos de 1999 e 2018, ordenados de acordo com a participação observada no último ano.

Tabela 4 - Distribuição dos valores contratados no PRONAF Custeio, por tipo de lavoura, 1999/2018

\begin{tabular}{|c|c|c|c|c|}
\hline \multirow{2}{*}{ Lavouras } & \multicolumn{2}{|c|}{ Valor (R\$ mil, a preços correntes) } & \multicolumn{2}{|c|}{ Participação no valor total (\%) } \\
\hline & 1999 & 2018 & 1999 & 2018 \\
\hline Soja & 111.787 & 3.006 .888 & 15,5 & 40,4 \\
\hline Milho & 188.271 & 1.689 .620 & 26,0 & 22,7 \\
\hline Café & 25.240 & 779.267 & 3,5 & 10,5 \\
\hline Trigo & 12.872 & 585.806 & 1,8 & 7,9 \\
\hline Arroz & 30.100 & 193.648 & 4,2 & 2,6 \\
\hline Feijão & 43.854 & 99.540 & 6,1 & 1,3 \\
\hline Mandioca & 32.915 & 93.390 & 4,6 & 1,3 \\
\hline Outras & 277.968 & 987.438 & 38,5 & 13,3 \\
\hline Total & 723.006 & 7.435.597 & 100,0 & 100,0 \\
\hline
\end{tabular}

Fonte: BACEN, Matriz de Dados do Crédito Rural. Elaborado pelos autores.

A principal mudança ocorrida nestes vinte anos está no substancial aumento na participação de commodities agrícolas nos financiamentos de custeio de lavouras com recursos do PRONAF. Se considerarmos apenas a lavoura de soja, essa participação mais que duplica, passando de $15,5 \%$ para $40,4 \%$ dos recursos. O número de contratos relacionados evoluiu de 63.648 contratos em 1999 (13,5\% do total) para 90.712 contratos em 2018 (31,8\% do total). As três principais culturas responderam por $73,6 \%$ dos valores contratados em 2018 , uma variação absoluta de 28,6 pp na participação em duas décadas.

Já ao se observar o desempenho conjunto das lavouras de trigo, arroz, feijão e mandioca - vale dizer, de alimentos que se destinam diretamente à mesa dos brasileiros -, houve uma redução na participação, de 16,7\% em 1999 para 13,1\% em 2018, a qual só não foi mais 
expressiva graças à performance da lavoura de trigo, uma vez que as lavouras de arroz, feijão e mandioca registraram declínio em sua parcela relativa. Estes dados de financiamento de custeio com base em recursos do PRONAF impõem um questionamento à percepção simplificada de que a agricultura familiar produziria, basicamente, alimentos para o mercado interno, sem grande presença das commodities para exportação, as quais ficariam ao encargo da agricultura patronal ou empresarial.

\section{Considerações finais: síntese e avaliações críticas}

A evidência examinada neste artigo destaca algumas dimensões do desempenho do Programa Nacional de Fortalecimento da Agricultura Familiar (PRONAF) desde sua implementação no ano de 1995. A principal conclusão é que o PRONAF consistiu de uma bemsucedida experiência de política pública na alavancagem de recursos creditícios à agricultura familiar brasileira. Assim, os valores mobilizados para o segmento cresceram de forma contínua entre sua criação, sobretudo após 2003, e o ano de 2014, quando atingiu o pico de R\$ 31,4 bilhões a preços de 2018. Com a recessão econômica, todavia, os aportes do PRONAF reduziram-se substancialmente, fechando a série com um total de $R \$ 23,7$ bilhões em 2018. A expansão do montante contratado foi acompanhada por um forte crescimento no número de contratos até o ano de 2006. Neste ponto de máximo, os mais de 2,5 milhões de contratos correspondiam a quase $60 \%$ do número de estabelecimentos familiares no país, o que atesta a abrangência alcançada pelo programa. Desde então, no entanto, observou-se uma tendência de queda nesse número até atingir 1,23 milhão de contratos celebrados em 2018.

Ainda que os números gerais de seu desempenho indiquem efetividade da política, há dimensões específicas de sua performance que vêm recebendo avaliações críticas na literatura especializada. A primeira dessas críticas aponta para um viés de seletividade no acesso ao crédito do PRONAF. Assim, Grisa, Wesz Junior e Buchweitz (2014, p. 333) destacam que teria se reproduzido "[...] também nas características do público beneficiário certa dependência de trajetória e seletividade observada no crédito rural tradicional executado nas décadas de modernização da agricultura brasileira". Um dado que indica a exclusão de determinados públicos refere-se à participação irrelevante de grupos de menor renda e riqueza, como os pescadores, silvicultores, aquicultores, extrativistas, quilombolas e silvícolas, os quais, em conjunto, responderam por cerca de $0,1 \%$ do número de contratos e dos valores financiados do PRONAF no quinquênio 2013-2017. De modo mais abrangente, podemos considerar que a tendência de crescimento do valor real médio contratado, que passou de $R \$ 5.469$ em 2006 para $\mathrm{R} \$ 19.238$ em 2018, a preços deste ano, em paralelo à redução no número de contratos da ordem de $51,7 \%$ no mesmo intervalo, indicaria a exclusão dos agricultores familiares menos capitalizados e/ou em condições percebidas como de maior risco pelo sistema bancário.

Ao se defrontarem com a questão dos motivos da exclusão de determinados públicos potencialmente beneficiários do programa, Grisa e Schneider $(2014$, p. 90) assinalam que: 
Son numerosos los estudios que relatan el desconocimiento y las dificultades de ciertos agricultores familiares para acceder a la DAP, como la falta de documentos personales, la exigencia de presentación de un documento comprobatorio de propiedad de la tierra a ser explotada, la falta de infraestructura (recursos humanos e internet) de las entidades responsables por la emisión de la declaración y el cobro indebido del servicio. Se trata, de este modo, de una institución que, al tiempo que orienta y posibilita el acceso de los agricultores familiares a las políticas públicas, también restringe la participación de ellos, limitando la atención de la diversidad social y económica de la categoría social.

Um segundo elemento de crítica ao desempenho do PRONAF, intimamente associado com o anterior, refere-se à concentração regional na distribuição dos recursos. Assim, já ao término do primeiro decênio de sua execução, Mattei (2006, p. 45) apontava que:

Os primeiros estudos relativos às operações de crédito rural do Pronaf demonstraram a existência de diversos problemas básicos das políticas agrícolas de fomento à produção, destacando-se dentre eles a excessiva concentração de recursos na região Sul do país e, particularmente dentro desta, em alguns produtos agroindustriais, como foi o caso do fumo.

Dez anos mais tarde, Búrigo, Capellesso e Cazella (2015) destacariam a permanência do que sempre foi visto como um problema:

\begin{abstract}
Apesar dos diversos ajustes efetuados, especialmente, durante os mandatos do presidente Lula, no sentido de democratizar a aplicação de seus recursos, o acesso ao Pronaf continua desigual e insuficiente face ao universo e ao perfil do público potencialmente beneficiário. Além de problemas de natureza institucional e técnica, que dificultam que os serviços de apoio e assistência cheguem de maneira abrangente aos agricultores familiares mais pobres, nota-se que suas verbas continuam primordialmente dirigidas para os sistemas de agricultura integrados às cadeias produtivas mais dinâmicas sob o ponto de vista produtivo e econômico, localizadas, especialmente, na macrorregião Sul do país.
\end{abstract}

Quanto a este aspecto, os dados são eloquentes: em três anos examinados neste artigo, correspondentes ao final de cada uma das décadas de execução do PRONAF, o montante de valores destinados à região Sul foi sempre superior a 50\%, não obstante essa região possuir menos de um quinto dos estabelecimentos familiares. No perfil detalhado sobre a distribuição dos recursos no ano de 2018, observa-se que o Sul celebrou 32,2\% dos contratos e recebeu $56,5 \%$ dos recursos, com valor médio de $\mathrm{R} \$ 33.620$, enquanto a região Nordeste, onde se localiza metade dos estabelecimentos familiares, teria respondido por $46,7 \%$ dos contratos e apenas $12,8 \%$ dos recursos, o que correspondeu a um valor médio financiado bem menor e igual a $\mathrm{R} \$$ 5.280 .

Um terceiro aspecto de desempenho que também vem recebendo o olhar crítico na literatura sobre o tema refere-se à mudança no perfil das culturas financiadas. $O$ sinal mais evidente dessa mudança está no crescimento da participação da lavoura de soja nos recursos financiados, saltando de 15,5\% em 1999 para 40,4\% em 2018. Também merece destaque, nesta comparação, o ganho de participação da lavoura de café e a virtual estabilidade na lavoura de milho. Ao coligirem fontes variadas na literatura, Grisa, Wesz Junior e Buchweitz (2014, p. 336337) produzem uma síntese esclarecedora: 
De modo geral, pode-se dizer que estes produtos, devido às suas características de produção e comercialização, restringem os 'espaços de manobra' das unidades familiares de produção. Trata-se de lavouras geralmente associadas à monocultura, a escalas de produção, à crescente 'externalização' da atividade produtiva e à dependência das grandes empresas do sistema agroindustrial [...]. As características desses cultivos sinalizam um caráter produtivista do Pronaf, [...], reproduzindo certa seletividade em termos de produtos financiados pelo Sistema Nacional de Crédito Rural.

Os argumentos críticos que assinalamos fornecem uma chave de compreensão para uma das críticas mais relevantes feitas ao PRONAF no debate público envolvendo atores políticos relacionados ao tema, qual seja, a de que o Programa tem feito "mais do mesmo", alocando parte majoritária de seus recursos ao mainstream da agricultura convencional. Assim, ao concentrar financiamentos na lavoura de soja, o PRONAF jogaria "água no moinho da Monsanto" e de outras transnacionais ligadas à sua cadeia produtiva, o que afronta as reivindicações originais dos agricultores familiares que pressionaram pela criação do programa e as expectativas de que o mesmo serviria para diversificar a atividade agrícola e garantir segurança alimentar aos brasileiros.

Nesta avaliação dos resultados da evolução do crédito rural do PRONAF, destacamos a magnitude assumida pelo programa. Trata-se do maior programa de financiamento da agricultura familiar no hemisfério sul, inspirado nos gigantescos sistemas de financiamento deste segmento da atividade agrícola existentes nos Estados Unidos e na União Europeia. No caso norte-americano, o sistema é oriundo da Triple A - Agricultural Adjustment Administration, criado no contexto do New Deal em 1933 e que permanece em vigor até os dias de hoje; na Europa, o sistema de financiamento tem origem na Política Agrícola Comum (PAC), criada em 1962 e, da mesma forma, ainda em vigor. Os programas europeu e norte-americano têm o princípio da segurança alimentar como uma de suas premissas básicas. Nos EUA, o Triple A foi uma das medidas adotadas em reação ao empobrecimento e à carestia provocados pela Grande Depressão iniciada em 1929, ao passo que, na Europa, a iniciativa da PAC é explicada pela experiência da fome vivenciada por suas populações durante as grandes guerras do século XX.

No momento de sua criação, consideravam-se como objetivo primordiais do PRONAF: melhorar a inserção produtiva de um enorme contingente de agricultores familiares que havia sido alijado do acesso ao crédito rural até então existente, aumentar a produção de alimentos e garantir a segurança alimentar no Brasil. À luz da evidência quanto aos valores e número de contratos, ressalvado o viés de seletividade quanto a públicos específicos, o programa teria logrado razoável êxito quanto ao primeiro objetivo. Já em relação ao segundo objetivo, em especial no que se refere à segurança alimentar, os dados não permitem conclusão semelhante. Financia-se cada vez mais as lavouras de soja, milho e café - nos primeiros anos, a atividade de fumo/tabaco, até que lhe fosse vedado o financiamento - e cada vez menos as lavouras de arroz, feijão e mandioca. Esta característica da evolução do programa, com volumosos recursos direcionados à produção de commodities agrícolas exportáveis, associa-se a outra de suas características, que é a forte absorção de recursos na região Sul do país, onde se localiza um contingente de agricultores familiares mais capitalizado e, também, o mais envolvido na lavoura de soja. Passados mais de vinte anos de sua implementação, caberia pensar sobre a necessidade de uma inflexão no PRONAF com base nos propósitos originais da segurança alimentar e da 
redução da pobreza rural, adotando-se medidas efetivas em direção aos agricultores familiares menos capitalizados, às culturas alimentares propriamente ditas e à ampliação do acesso dos públicos não convencionais.

\section{Referências}

ABRAMOVAY, R. Paradigmas do capitalismo agrário em questão. 2. ed. São Paulo: Hucitec, 1998.

BANCO CENTRAL DO BRASIL - BACEN. Resolução n. 2191, de 24 de agosto de 1995. Crédito Rural - Institui o Programa Nacional de Fortalecimento da Agricultura Familiar (PRONAF).

BIANCHINI, V. Vinte anos do PRONAF, 1995 a 2015: avanços e desafios. Brasília: SAF/MDA, 2015.

BRASIL. Medida Provisória n. 1.911-12, de 25 de novembro de 1999. Altera dispositivos da Lei n. 9.649, de 27 de maio de 1998, que dispõe sobre a organização da Presidência da República e dos Ministérios, e dá outras providências. Disponível em:

<http://www.planalto.gov.br/ccivil_03/mpv/antigas/1911-12.htm>. Acesso em: 08 nov. 2018.

. Medida Provisória n. 1.999-14, de 13 de janeiro de 2000. Altera dispositivos da Lei n. 9.649, de 27 de maio de 1998, que dispõe sobre a organização da Presidência da República e dos Ministérios, e dá outras providências. Disponível em:

<http://www.planalto.gov.br/ccivil_03/mpv/antigas/1999-14.htm>. Acesso em: 08 nov. 2018.

. Lei n. 10.683, de 28 de maio de 2003. Dispõe sobre a organização da Presidência da República e dos Ministérios, e dá outras providências. Disponível em:

<http://www.planalto.gov.br/CCivil_03/Leis/2003/L10.683.htm>. Acesso em: 08 nov. 2018.

. Lei n. 11.326, de 24 de julho de 2006. Estabelece as diretrizes para a formulação da Política Nacional da Agricultura Familiar e Empreendimentos Familiares Rurais. Disponível em: <http://www.planalto.gov.br/ccivil_03/_ato2004-2006/2006/lei/l11326.htm>. Acesso em: 08 nov. 2018.

. Medida Provisória n. 726, de 12 de maio de 2016. Altera e revoga dispositivos da Lei n. 10.683 , de 28 de maio de 2003, que dispõe sobre a organização da Presidência da República e dos Ministérios. Disponível em: <http://www.planalto.gov.br/ccivil_03/_ato2015-

2018/2016/mpv/mpv726.htm>. Acesso em: 08 nov. 2018.

. Decreto n. 8.780, de 27 de maio de 2016. Transfere a Secretaria Especial de Agricultura Familiar e do Desenvolvimento Agrário para a Casa Civil da Presidência da República. Disponível em: <http://www.planalto.gov.br/ccivil_03/_ato2015-2018/2016/decreto/d8780.htm>. Acesso em: 08 nov. 2018.

. Lei n. 13.341, de 29 de setembro de 2016. Altera as Leis n. 10.683, de 28 de maio de 2003, que dispõe sobre a organização da Presidência da República e dos Ministérios, e 11.890, de 24 de dezembro de 2008, e revoga a Medida Provisória n. 717, de 16 de março de 2016. Disponível em: <http://www.planalto.gov.br/ccivil_03/_ato2015-2018/2016/Lei/L13341.htm>. Acesso em: 08 nov. 2018. 
. Decreto n. 9.064, de 31 de maio de 2017. Dispõe sobre a Unidade Familiar de Produção Agrária, institui o Cadastro Nacional da Agricultura Familiar e regulamenta a Lei n. 11.326, de 24 de julho de 2006, que estabelece as diretrizes para a formulação da Política Nacional da Agricultura Familiar e empreendimentos familiares rurais. Disponível em:

<http://www.planalto.gov.br/ccivil_03/_Ato2015-2018/2017/Decreto/D9064.htm>. Acesso em: 08 nov. 2018.

BÚRIGO, F.; CAPELLESSO, A. J.; CAZELLA, A. A. Evolução do PRONAF Crédito no período 19962013: redimensionando o acesso pelos cadastros de pessoa física. In: 53을 Congresso da SOBER, 2015, João Pessoa. Anais ... João Pessoa: SOBER, 2015. Disponível em:

<http://lemate.paginas.ufsc.br/files/2016/04/Artigo-Sober-CPF-Pronaf.pdf >. Acesso em: 09 nov. 2018.

FRANÇA, C. G. de; DEL GROSSI, M. E.; MARQUES, V. P. M. de. O censo agropecuário 2006 e a agricultura familiar no Brasil. Brasília: MDA, 2009.

GRISA, C.; SCHNEIDER, S. Brasil: dos décadas de políticas públicas para la agricultura familiar. In: SABOURIN, E.; SAMPER, M.; SOTOMAYOR, O. (Coord.). Políticas públicas y agriculturas familiares en América Latina y el Caribe: balance, desafíos y perspectivas. Santiago, Chile: CEPAL, 2014. Cap. IV.

GRISA, C.; WESZ JUNIOR, V. J.; BUCHWEITZ, V. D. Revisitando o Pronaf: velhos questionamentos, novas interpretações. Revista de Economia e Sociologia Rural, Sorocaba, v. 52, p. 323-346, abr./jun. 2014.

GUANZIROLI, C. E.; CARDIM, S. E. de C. S. (coord.). Novo retrato da agricultura familiar: o Brasil redescoberto. Projeto de cooperação técnica INCRA/FAO. Brasília: INCRA; FAO, mar. 2000. mimeo. Disponível em: <https://www.agencia.cnptia.embrapa.br/recursos/novoretratolD3iTs4E7R59.pdf>. Acesso em: 09 nov. 2018.

MATTEI, L. Pronaf 10 anos: mapa da produção acadêmica. Brasília: MDA, 2006.

NUNES, S. P. O crédito rural do Pronaf e os recentes instrumentos de política agrícola para a agricultura familiar, Departamento de Estudos Sócio-Econômicos Rurais, DESER, Conjuntura Agrícola, n. 156, fev. 2007. Disponível em:

<http://www.deser.org.br/documentos/imagem/Pronaf.pdf>. Acesso em: 08 nov. 2018. 